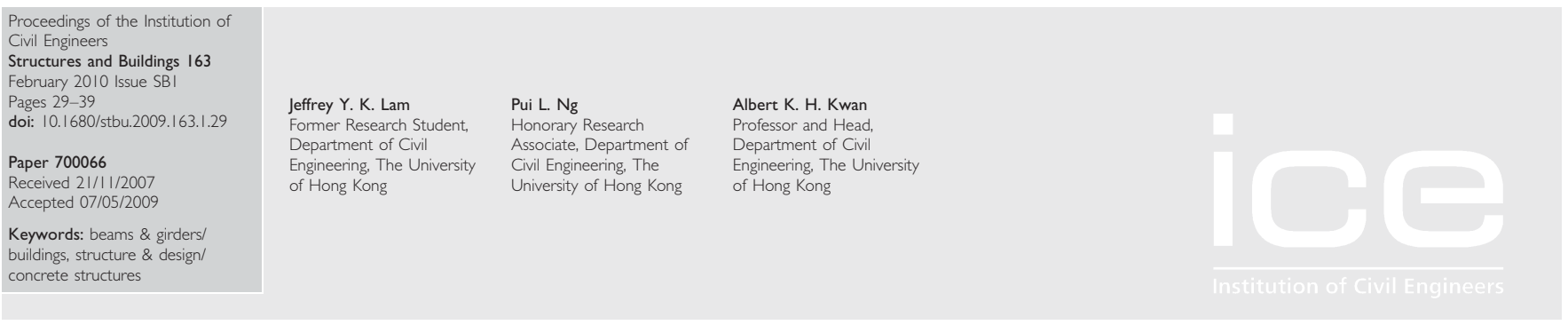

\title{
Tension stiffening in concrete beams. Part 2: member analysis
}

\author{
J. Y. K. Lam PhD, P. L. Ng PhD and A. K. H. Kwan PhD, MICE, CEng
}

Based on finite-element analysis of cracked reinforced concrete beams, a tensile stress block was proposed in part I of this paper. Here, the proposed tensile stress block is contrasted with existing ones developed by others to provide an overall review. The proposed tensile stress block is then applied to a section analysis of beams to evaluate the moment-curvature curves of typical beam sections. The section analysis results are compared with available experimental results and empirical curves given in design codes to demonstrate the validity of the tensile stress block. Subsequently, the proposed tensile stress block is applied to member analysis by first dividing the beam member into short segments and then applying section analysis to each segment to evaluate the loaddeflection curves of typical beam members. The member analysis results are checked against finite-element analysis results and available experimental results to fine-tune the tensile stress block and verify the accuracy of the finetuned tensile stress block. Such member analysis could be extended to multi-level analysis of frame structures for their full-range load-deflection behaviour at the elastic, post-crack and post-peak states.

\section{INTRODUCTION}

As tension stiffening might contribute significantly to the flexural stiffness of reinforced concrete members after the concrete has cracked (as shown by Gilbert and Warner (1978), it could be up to $100 \%$ ), it is important to model the tension stiffening effect properly for accurate analysis of the deflection of reinforced concrete beams and slabs under service load. There are two basic approaches for taking into account the tension-stiffening effect when analysing the deflection of flexural members.

The first approach is to directly generate the momentcurvature curve of the reinforced concrete section with tension stiffening taken into account. Branson (1968) proposed that the effective moment of inertia $I_{\text {eff }}$ of the section may be adjusted according to the state of cracking and the applied moment as per Equation 1 to allow for the tension stiffening effect

$$
I_{\text {eff }}=I_{\text {cr }}+\left(I_{\mathrm{g}}-I_{\mathrm{cr}}\right)\left(\frac{M_{\mathrm{cr}}}{M}\right)^{n}
$$

where $I_{\mathrm{g}}$ is the moment of inertia before cracking, $I_{\mathrm{cr}}$ is the moment of inertia when fully cracked, $M_{\mathrm{cr}}$ is the cracking moment, $M$ is the applied moment and $n$ is a dimensionless factor. This approach is adopted in the ACI building code (ACI, 2008) with $n$ set equal to 3.0. Instead of working with the moment of inertia, CEB-FIP Model Code 1990 (CEB, 1993) and Eurocode 2 (CEN, 2005) work with the curvature of the section. In particular, Eurocode 2 provides the following formula for the curvature $\psi$ of the section

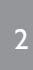

$$
\psi=\psi_{2}+\left(\psi_{1}-\psi_{2}\right) \beta\left(\frac{M_{\mathrm{cr}}}{M}\right)^{2}
$$

in which $\psi_{1}$ is the curvature if the section remains uncracked, $\psi_{2}$ is the curvature if the section is fully cracked and $\beta$ is a coefficient taking account of the influence of the duration of loading or of repeated loading $(\beta=1.0$ for a single short-term load and $\beta=0.5$ for a sustained load or many cycles of repeated load).

The second approach is to allow for the tensile stresses induced in the concrete between adjacent cracks by means of a tensile stress block. Many tensile stress blocks have been developed. Gilbert and Warner (1978) considered three tensile stress blocks, all having linear ascending branches but one with a discontinuous saw tooth descending branch, another with a continuous non-linear descending branch and a third with a discontinuous multi-linear descending branch. Carreira and Chu (1986) used the stress-strain curve of concrete under direct tension, which is a continuous non-linear curve, as the tensile stress block. Prakhya and Morley (1990) followed Carreira and Chu's curve but modified the shape of the curve to fit the experimental results obtained by Clark and Speirs (1978) and Clark and Cranston (1979). Damjanic and Owen (1984) adopted a tensile stress block with a linear ascending branch and a discontinuous linear descending branch. Schnobrich (1985) adopted a tensile stress block with a linear ascending branch and a continuous linear descending branch derived from in-plane tests of concrete. Kaklauskas and Ghaboussi (2001) derived the tensile stress block by back-calculating from the experimental results of Clark and Speirs (1978). Torres et al. (2004) derived the tensile stress block by fitting it with the empirical moment-curvature curves given in Eurocode 2 (CEN, 2005). Scott (1983) and Beeby et al. (2005) proposed the use of tensile stress blocks each comprising multi-linear ascending and descending branches. 
Relatively speaking, the second approach of using a tensile stress block to allow for the tension stiffening effect is more generally applicable. In theory, it is applicable to any arbitrarily shaped (rectangular or non-rectangular) frame members (columns and beams) with or without axial loads and subjected to uniaxial or biaxial bending. Moreover, while the empirical moment-curvature curves given in the design codes are applicable only to analysis under the servicing condition well before the peak moments are reached, tensile stress blocks can be applied to full-range analysis under both servicing and ultimate conditions.

Some of the above-mentioned tensile stress blocks and the one given in BS 8110 (BSI, 1985) are shown in Figure 1 for comparison. It is evident from this figure that the existing tensile stress blocks differ widely. Since the tensile stress block could significantly affect moment-curvature and loaddeflection curves, it is vital to adopt an appropriate one for analysis. However, the large differences between the existing tensile stress blocks make it difficult to judge which particular one is more appropriate. Part 1 of this paper ( $\mathrm{Ng}$ et al., 2010) proposed a new tensile stress block based on finite-element (FE) analysis of the tension stress fields in typical reinforced concrete beams. This new tensile stress block is probably the first one developed by direct determination of the actual distribution of mean tensile stress within the beam depth. In this paper, the newly developed tensile stress block is compared with existing ones, applied to section analysis to evaluate the accuracy of the resulting moment-curvature curves and then applied to member analysis to evaluate the

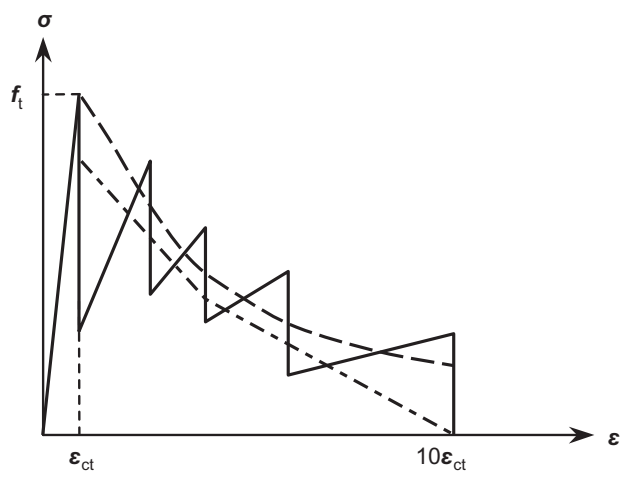

(a) Gilbert and Warner (1978)

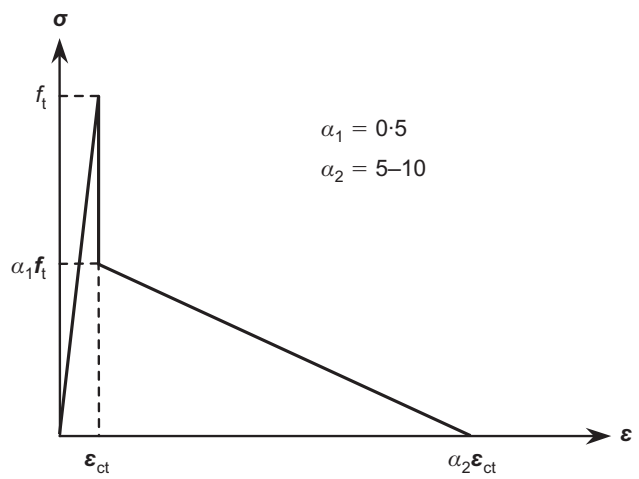

(c) Damjanic and Owen (1984)

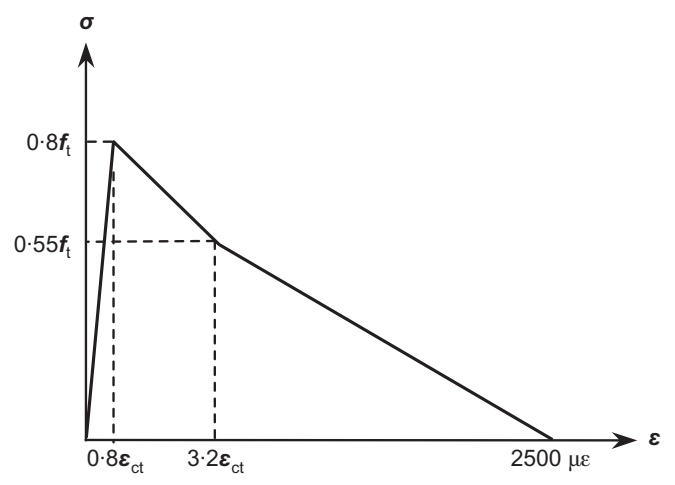

(e) Beeby et al. (2005)

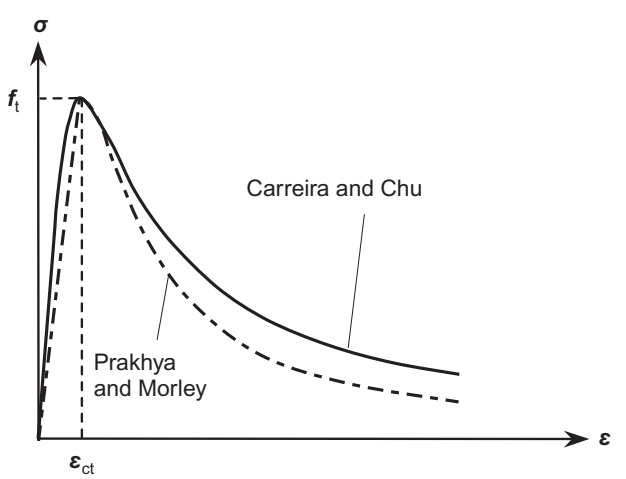

(b) Carreira and Chu (1986) and Prakhya and Morley (1990)

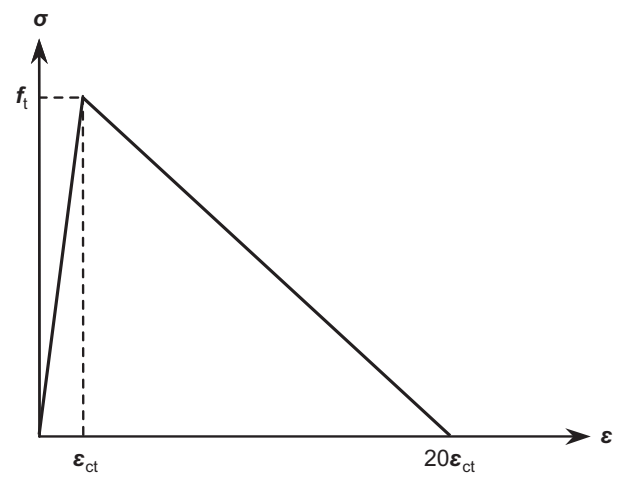

(d) Schnobrich (1985)

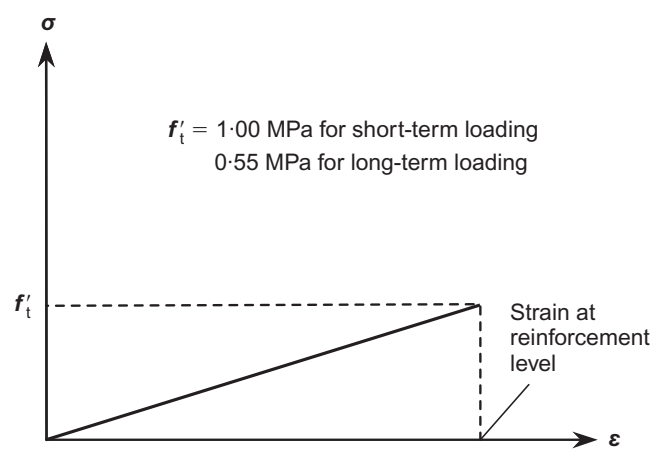

(f) BS 8110 (1985)

\section{Figure I. Existing tensile stress blocks}


accuracy of the resulting load-deflection curves. Moreover, a multi-level analysis method (combining section and member analysis) for the non-linear load-deflection analysis of frame structures is presented.

\section{REVIEW OF EXISTING TENSILE STRESS BLOCKS}

Full-field and accurate measurement of tensile stresses in a cracked concrete beam is extremely difficult. For this reason, the existing tensile stress blocks have, in general, been developed by proposing a certain tensile stress block with unknown parameters and determining the unknown parameters by curve fitting of theoretical moment-curvature or loaddeflection curves obtained from experiment.

Among the three stress blocks considered by Gilbert and Warner (1978), they found that the one with a discontinuous saw tooth descending branch and the one with a discontinuous multi-linear descending branch could fit well with experimental results. The one with a continuous nonlinear descending branch did not fit the experimental results well.

Carreira and Chu (1986) found that their proposed continuous stress-strain curve for the stress block fitted the experimental results well only when the shape of the curve was adjusted each time according to the experimental results. They have not arrived at any generally applicable stress block. On the other hand, Prakhya and Morley (1990) modified Carreira and Chu's curve to have a linear ascending branch and, by fitting with available experimental results, derived an empirical formula for the parameter defining the shape of the descending branch of the curve. They thus arrived at a more generally applicable stress block.

The four stress blocks adopted by Damjanic and Owen (1984), Schnobrich (1985), Kaklauskas and Ghaboussi (2001) and Torres et al. (2004) are characterised by each having a linear ascending branch and a linear descending branch. Schnobrich's stress block is continuous in the sense that the descending branch is continuous with the ascending branch, whereas the other three stress blocks are discontinuous because of the abrupt drop in stress after reaching the peak. Nevertheless, these stress blocks can all be defined in terms of two parameters, $\alpha_{1}$ and $\alpha_{2}$, as depicted in Figure 2.

The stress blocks proposed by Scott (1983) and Beeby et al. (2005) are characterised by continuous multi-linear ascending and descending branches. According to Beeby et al., there could be rapid decay of the tension stiffening effect within a certain time after loading and therefore, when measuring the tension-stiffening effect in tests, the rapid decay must be taken into account.

Lastly, the stress block given in BS 8110 (BSI, 1985) is just a linear ascending curve with no descending branch. No justification for this stress block could be found and it is difficult to understand why the stress block should be like this.

In part 1 of this paper ( $\mathrm{Ng}$ et al., 2010), the tension stress fields in typical reinforced concrete beams were analysed by the FE method. It was found that before cracking, the mean tensile stress-theoretical tensile strain curve is a straight line

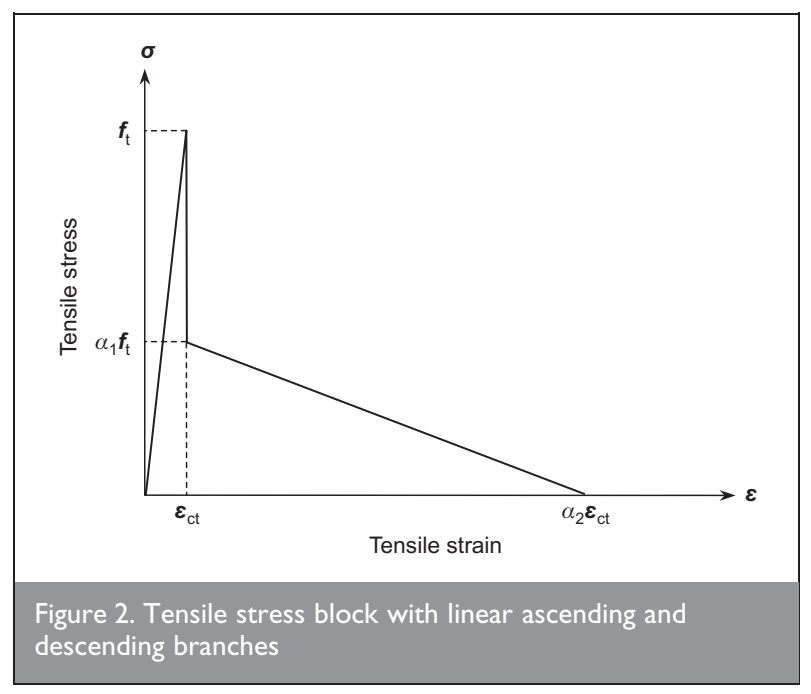

ascending to the tensile strength of concrete; after cracking, the curve comprises a non-linear ascending branch reaching to about half of the tensile strength of concrete and a descending branch with a long tail. Hence, in theory, two distinct stress blocks, one for the pre-crack state and the other for the postcrack state, should be adopted.

For practical applications, it is proposed to combine the two stress blocks into one consisting of a linear ascending branch and a discontinuous linear descending branch (like the existing stress blocks with linear ascending and descending branches), as shown in Figure 2. The proposed stress block is given by

$$
\text { 3a } \quad \boldsymbol{\sigma}=\boldsymbol{E}_{\mathrm{co}} \boldsymbol{\varepsilon} \text { for } \boldsymbol{\varepsilon} \leqslant \boldsymbol{\varepsilon}_{\mathrm{ct}}
$$$$
\text { 3a } \quad \boldsymbol{\sigma}=\frac{\alpha_{1} \boldsymbol{f}_{\mathrm{t}}\left(\alpha_{2} \boldsymbol{\varepsilon}_{\mathrm{ct}}-\boldsymbol{\varepsilon}\right)}{\left(\alpha_{2} \boldsymbol{\varepsilon}_{\mathrm{ct}}-\boldsymbol{\varepsilon}_{\mathrm{ct}}\right)} \text { for } \boldsymbol{\varepsilon}_{\mathrm{ct}}<\boldsymbol{\varepsilon} \leqslant \alpha_{2} \boldsymbol{\varepsilon}_{\mathrm{ct}}
$$$$
\begin{array}{|c|c|}
\hline 3 c & \boldsymbol{\sigma}=0 \text { for } \alpha_{2} \boldsymbol{\varepsilon}_{\mathrm{ct}}<\boldsymbol{\varepsilon}
\end{array}
$$

in which $\boldsymbol{\sigma}$ and $\boldsymbol{\varepsilon}$ are the stress and strain, $\boldsymbol{E}_{\mathrm{co}}$ is the initial elastic modulus, $\boldsymbol{f}_{\mathrm{t}}$ is the tensile strength and $\boldsymbol{\varepsilon}_{\mathrm{ct}}$ is the tensile strain at peak tensile stress $\left(\boldsymbol{\varepsilon}_{\mathrm{ct}}=\boldsymbol{f}_{\mathrm{t}} / \boldsymbol{E}_{\mathrm{co}}\right)$.

Although the existing stress blocks with linear ascending and descending branches and the proposed stress block have similar shapes, their respective $\alpha_{1}$ and $\alpha_{2}$ values (summarised in Table 1 for comparison) are not quite the same. Damjanic and Owen (1984) suggested a constant value of 0.5 for $\alpha_{1}$ and a typical range of 5-10 for $\alpha_{2}$. Schnobrich (1985) adopted a constant value of 1.0 for $\alpha_{1}$ and a constant value of 20 for $\alpha_{2}$. Kaklauskas and Ghaboussi (2001) proposed a typical range of 0.6-0.7 for $\alpha_{1}$ and a range of 6-27 depending on $\rho_{\mathrm{t}}$ (the tension reinforcement ratio) for $\alpha_{2}$. Torres et al. (2004) derived the value of $\alpha_{1}$ as 0.40 or 0.45 depending on the applied moment and the value of $\alpha_{2}$ as 7-27 depending on both $\rho_{\mathrm{t}}$ and $d / h(d / h$ is the effective depth to total depth ratio). In contrast, the proposed stress block has $\alpha_{1}$ and $\alpha_{2}$ values that depend only on the type of loading: for a point load (PL), $\alpha_{1}=0 \cdot 4$ and 


\begin{tabular}{|c|c|c|}
\hline Tensile stress block & $\alpha_{1}$ & $\alpha_{2}$ \\
\hline Damjanic and Owen (1984) & 0.5 & 5-10 (typical range) \\
\hline Schnobrich (1985) & 1.0 & 20 (constant value) \\
\hline Kaklauskas and Ghaboussi (200I) & $0.6-0.7$ (typical range) & $6-27$ (depending on $\rho_{t}{ }^{*}$ ) \\
\hline Torres et al. (2004) & $\begin{array}{l}\alpha_{1}=0.40 \text { if } M \geqslant 1.25 M_{c r} \\
\alpha_{1}=0.45 \text { if } M<1.25 M_{c r}\end{array}$ & 7-27 (depending on $\rho_{t}$ and $\mathrm{d} / \mathrm{h} \dagger$ ) \\
\hline Proposed stress block & $\begin{array}{l}\alpha_{1}=0.40 \text { for a PL } \ddagger \\
\alpha_{1}=0.50 \text { for a UDL } \S\end{array}$ & $\begin{array}{l}\alpha_{2}=18 \text { for a PL } \\
\alpha_{2}=14 \text { for a UDL }\end{array}$ \\
\hline
\end{tabular}

$* \rho_{t}$ is tension reinforcement ratio

$\dagger d / h$ is effective depth to total depth ratio

$\ddagger$ Point load

$\S$ Uniformly distributed load

Table I. Tensile stress blocks with linear ascending and descending branches

$\alpha_{2}=18$; for a uniformly distributed load (UDL), $\alpha_{1}=0.5$ and $\alpha_{2}=14$.

\section{SECTION ANALYSIS}

\section{I. Material modelling}

For the concrete, it is assumed that when under tension the stress-strain relation follows the proposed tensile stress block and when under compression the stress-strain relation follows the equation proposed by Saenz (1964). On the other hand, for the steel reinforcement, the stress-strain relation is assumed to be elasto-plastic with strain hardening when under tension or compression. These assumed stress-strain relations are plotted in Figure 3 for illustration.

\subsection{Method of analysis}

The method of analysis employed here is a modified version of the method developed by Liauw and Kwan (1984) and Kwan and Liauw (1985), which is applicable to any arbitrary shaped section subjected to axial load and biaxial bending. Two common assumptions are made in the analysis

(a) plane sections remain plane after bending

(b) there is perfect bond between the steel reinforcement and the concrete.

Secant stiffness is used in the formulation.

A rectangular coordinate system is adopted to define the location of any point in the section. Let the coordinates of a certain point in the section be $(x, y)$. Following the assumption that plane sections remain plane after bending, the distribution of the axial strain $\boldsymbol{\varepsilon}$ in the section is a linear function of the $x$ and $y$-coordinates, as given by

$$
\boldsymbol{\varepsilon}=\boldsymbol{\varepsilon}_{0}+\kappa_{y} x+\kappa_{x} y
$$

where $\boldsymbol{\varepsilon}_{0}$ is the axial strain at the origin of the coordinate system, $\kappa_{x}$ is the curvature about the $x$-axis and $\kappa_{y}$ is the curvature about the $y$-axis. As a perfect bond is assumed, this equation is applicable to both the concrete and the steel reinforcement.

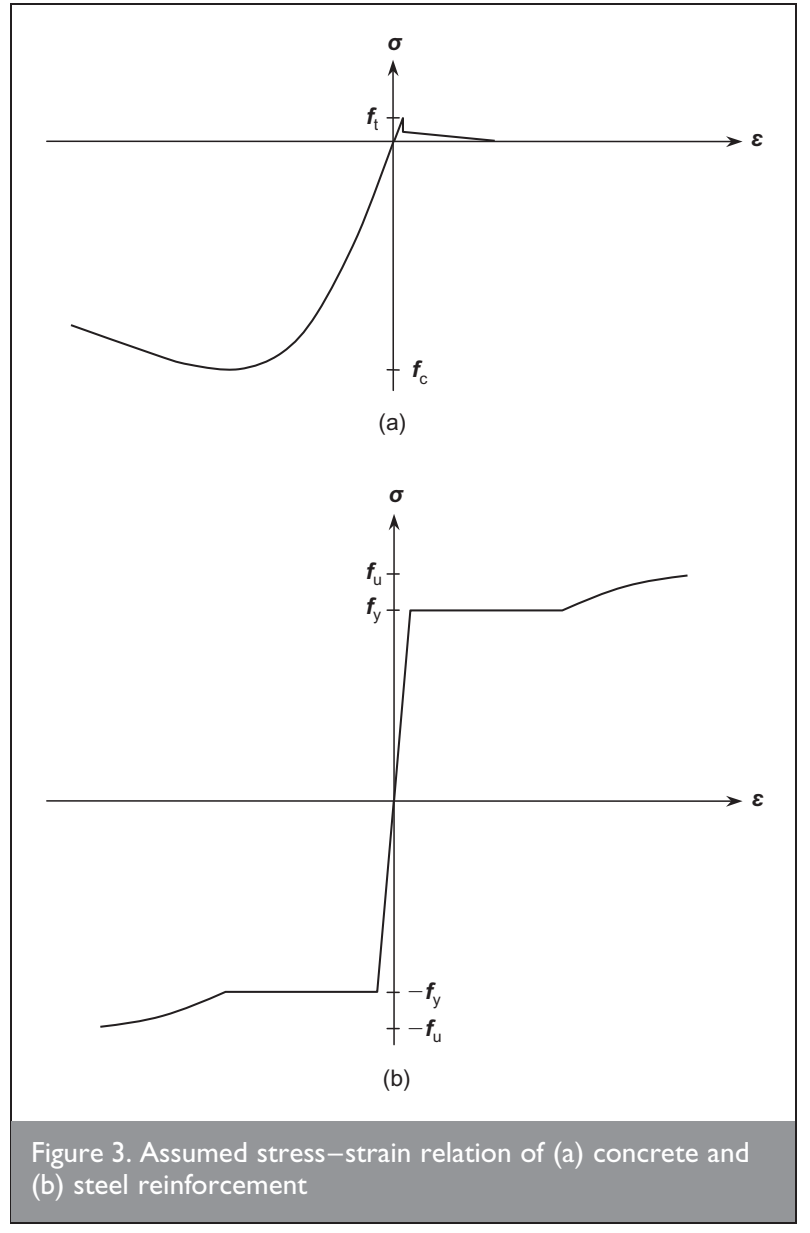

The axial stresses developed in the section have to satisfy the following axial and moment equilibrium equations

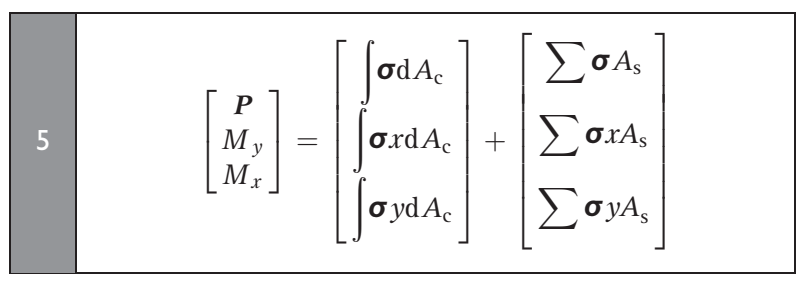


in which $\boldsymbol{P}$ is the axial load, $M_{\mathrm{x}}$ and $M_{\mathrm{y}}$ are the bending moments about the $x$-axis and $y$-axis respectively, $\sigma$ is the axial stress, $A_{\mathrm{c}}$ is the area of concrete, $A_{\mathrm{s}}$ is the area of steel reinforcement; the integrations are to be applied over the whole area of concrete and the summations are to be applied to all steel reinforcing bars.

The axial stresses in the concrete and the steel reinforcement may be expressed as $\boldsymbol{E}_{\mathrm{c}} \boldsymbol{\varepsilon}$ and $\boldsymbol{E}_{\mathrm{s}} \boldsymbol{\varepsilon}$, respectively, in which $\boldsymbol{E}_{\mathrm{c}}$ is the secant modulus of the concrete and $\boldsymbol{E}_{\mathrm{s}}$ is the secant modulus of the steel reinforcement. Expressing the axial stress $\boldsymbol{\sigma}$ in terms of the axial strain $\boldsymbol{\varepsilon}$ and substituting the axial strain $\boldsymbol{\varepsilon}$ by the linear function given in Equation 4, Equation 5 becomes

$$
\left[\begin{array}{c}
\boldsymbol{P} \\
M_{y} \\
M_{x}
\end{array}\right]=[\mathbf{S}]\left[\begin{array}{c}
\boldsymbol{\varepsilon}_{0} \\
\kappa_{y} \\
\kappa_{x}
\end{array}\right]=\left\{\left[\mathbf{S}_{\mathrm{c}}\right]+\left[\mathbf{S}_{\mathbf{S}}\right]\right\}\left[\begin{array}{c}
\boldsymbol{\varepsilon}_{\mathrm{o}} \\
\kappa_{y} \\
\kappa_{x}
\end{array}\right]
$$

where $[\mathrm{S}]$ is the section stiffness matrix, and $\left[\mathrm{S}_{\mathrm{c}}\right]$ and $\left[\mathrm{S}_{\mathrm{s}}\right]$ are given by

$\mathrm{F}_{\mathrm{a}} \quad\left[\mathrm{S}_{\mathrm{c}}\right]=\left[\begin{array}{ccc}\int \boldsymbol{E}_{\mathrm{c}} \mathrm{d} A_{\mathrm{c}} & \boldsymbol{E}_{\mathrm{c}} x \mathrm{~d} A_{\mathrm{c}} & \int \boldsymbol{E}_{\mathrm{c}} y \mathrm{~d} A_{\mathrm{c}} \\ \int \boldsymbol{E}_{\mathrm{c}} x \mathrm{~d} A_{\mathrm{c}} & \int \boldsymbol{E}_{\mathrm{c}} x^{2} \mathrm{~d} A_{\mathrm{c}} & \boldsymbol{E}_{\mathrm{c}} x y \mathrm{~d} A_{\mathrm{c}} \\ \int \boldsymbol{E}_{\mathrm{c}} y \mathrm{~d} A_{\mathrm{c}} & \int \boldsymbol{E}_{\mathrm{c}} x y \mathrm{~d} A_{\mathrm{c}} & \int \boldsymbol{E}_{\mathrm{c}} y^{2} \mathrm{~d} A_{\mathrm{c}}\end{array}\right]$

$7 \mathrm{~b} \quad\left[\mathrm{~S}_{\mathrm{s}}\right]=\left[\begin{array}{ccc}\sum \boldsymbol{E}_{\mathrm{s}} A_{\mathrm{s}} & \sum \boldsymbol{E}_{\mathrm{s}} x A_{\mathrm{s}} & \sum \boldsymbol{E}_{\mathrm{s}} y A_{\mathrm{s}} \\ \sum \boldsymbol{E}_{\mathrm{s}} x A_{\mathrm{s}} & \sum \boldsymbol{E}_{\mathrm{s}} x^{2} A_{\mathrm{s}} & \sum \boldsymbol{E}_{\mathrm{s}} x y A_{\mathrm{s}} \\ \sum \boldsymbol{E}_{\mathrm{s}} y A_{\mathrm{s}} & \sum \boldsymbol{E}_{\mathrm{s}} x y A_{\mathrm{s}} & \sum \boldsymbol{E}_{\mathrm{s}} y^{2} A_{\mathrm{s}}\end{array}\right]$

Initially, before any loading is applied, the secant moduli $\boldsymbol{E}_{\mathrm{c}}$ and $\boldsymbol{E}_{\mathrm{s}}$ are each taken as the initial elastic modulus of the respective material. After loading is applied, the secant modulus $\boldsymbol{E}_{\mathrm{c}}$ or $\boldsymbol{E}_{\mathrm{s}}$ at any point in the section is determined as the ratio $\boldsymbol{\sigma} / \boldsymbol{\varepsilon}$ based on the axial stress and strain results obtained in the previous loading step.

The integration for evaluation of $\left[S_{c}\right]$ is performed by numerical integration using Gaussian quadrature. For arbitrary shaped sections, there are two viable methods. First, the section may be divided into a mesh of triangular elements using an automatic mesh generator and then the integration performed on each element, as proposed by Liauw and Kwan (1984). Alternatively, the area integration may be transformed into a boundary integration using Green's theorem and then the boundary integration performed by means of a boundary walk along the perimeter of the section, as proposed by Kwan and Liauw (1985).

The loads may be applied in the form of prescribed forces (prescribed values of $\boldsymbol{P}, M_{\mathrm{y}}$ and $M_{\mathrm{x}}$ ) or prescribed displacements (prescribed values of $\boldsymbol{\varepsilon}_{0}, \kappa_{y}$ and $\kappa_{x}$ ). In both cases, the unknown forces or displacements can be determined by just solving Equation 6. For generating the momentcurvature curve of a section subjected to a constant axial load and a uniaxial bending moment about the $x$-axis, the axial load $\boldsymbol{P}$ and the bending moment $M_{\mathrm{y}}$ should be applied as prescribed forces and the curvature $\kappa_{x}$ should be applied as a prescribed displacement in small increments. Since the actual computer time is insignificant, the loading process is simulated by applying the prescribed forces or displacements in more than 200 loading steps until the peak load or moment has been reached.

\subsection{Comparison with experimental results of Sakai and Kakuta (1980)}

In order to verify the validity and accuracy of the proposed tensile stress blocks and section analysis method, the beams tested by Sakai and Kakuta (1980) are analysed and the theoretical moment-curvature curves so obtained compared with experimental results. Two of the beams tested (beams M-13 and M-16) were selected for the analysis. Both beams have a uniform cross-section of $150 \mathrm{~mm}$ breadth by $300 \mathrm{~mm}$ depth and an effective depth of $270 \mathrm{~mm}$. They were each simply supported with a span of $3400 \mathrm{~mm}$ and subjected to two PLs applied at $1000 \mathrm{~mm}$ from the mid-span location. The material properties and details of the beams are given in Table 2. Apart from minor differences in material properties, the main difference between the two beams is that M-13 has a tension reinforcement ratio of $0.596 \%$ while M-16 has a tension reinforcement ratio of $0.932 \%$.

Two tensile stress blocks were used in the theoretical analysis. The first stress block is that for a PL, which has $\alpha$ values of $\alpha_{1}=0 \cdot 4$ and $\alpha_{2}=18$, whereas the second stress block is that for a UDL, $\alpha_{1}=0.5$ and $\alpha_{2}=14$. Figure 4 shows a comparison between theoretical results, experimental results and the empirical moment-curvature curves provided by the ACI building code (ACI, 2008) and Eurocode 2 (CEN, 2005). The figure shows that the moment-curvature curves given by the ACI building code and Eurocode 2 differ slightly. Nevertheless, for every beam, the experimental results fall between the moment-curvature curves given by the two codes. More importantly, for each beam, regardless of the tensile stress 


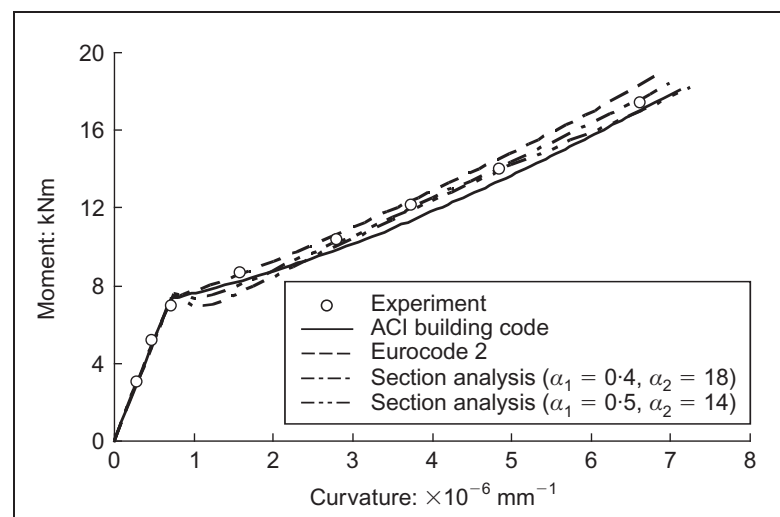

(a)

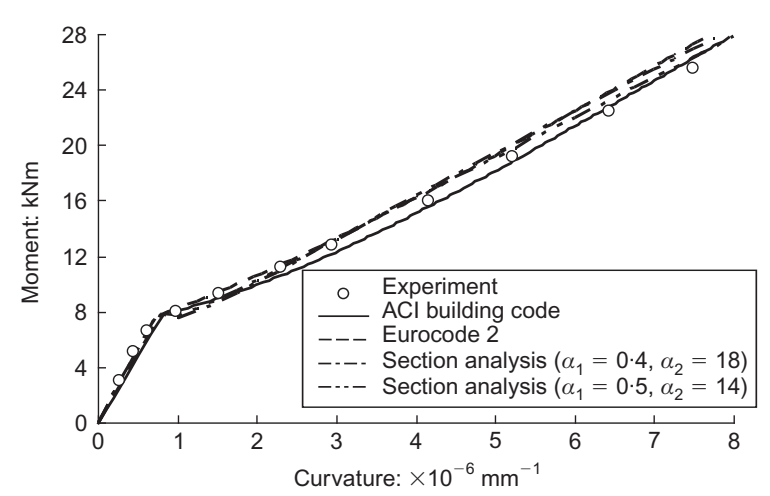

(b)

Figure 4. Comparison between section analysis results, experimental results of Sakai and Kakuta (1980) and empirical curves given in design codes: (a) beam M-I $3\left(\rho_{\mathrm{t}}=0.596 \%\right)$; (b) beam M-I6 $\left(\rho_{\mathrm{t}}=0.932 \%\right)$

block used, the theoretical moment-curvature curve agrees closely with the experimental results, thus verifying the validity of the proposed tensile stress blocks.

\section{MEMBER ANALYSIS}

\section{I. Method of analysis}

To analyse the load-deflection behaviour of a flexural member (such analysis is called member analysis), the member needs to be divided into many short segments with each short segment dealt with by section analysis. Each segment is treated as a frame element with two nodes and six degrees of freedom (dof) at each node. The six dof at each node are the three displacements along the three coordinate axes and the three rotations about the three coordinate axes, as in space frame analysis.

Let the two nodes be denoted $i$ and $j$. Following standard FE formulation, the axial strain $\boldsymbol{\varepsilon}_{0}$, curvature about $x$-axis $\kappa_{x}$ and curvature about $y$-axis $\kappa_{\mathrm{y}}$ at any location within the frame element may be expressed as

\begin{tabular}{|l|c|}
\hline 8 & {$\left[\begin{array}{c}\boldsymbol{\varepsilon}_{0} \\
\kappa_{y} \\
\kappa_{x}\end{array}\right]=[\mathbf{B}]\left[\begin{array}{c}\delta_{i} \\
\delta_{j}\end{array}\right]$} \\
\hline
\end{tabular}

in which $[\mathrm{B}]$ is the strain-displacement matrix, and $\left[\delta_{i}\right]$ and $\left[\delta_{j}\right]$ are the nodal dof at nodes $i$ and $j$. From [B], which defines the strain-displacement relation, the stiffness matrix $[\mathrm{K}]$ of the frame element may be derived as$$
[\mathrm{K}]=\int[\mathrm{B}]^{\mathrm{T}}[\mathrm{S}][\mathrm{B}] \mathrm{d} l
$$

in which the section stiffness matrix [S] is as given by Equations 6 and 7, and the integration is to be performed over the length of the frame element. For short frame elements, within which the variations of $\boldsymbol{\varepsilon}_{0}, \kappa_{x}$ and $\kappa_{y}$ should be small, the section stiffness matrix $[\mathrm{S}]$ may be assumed to be constant within each element. The above formulation is for threedimensional space frame analysis, which requires a $12 \times 12$ stiffness matrix. For two-dimensional plane frame analysis, the out-of-plane dof may simply be ignored to arrive at a $6 \times 6$ stiffness matrix.

\subsection{Numerical procedures}

The procedure to form the stiffness matrix of the flexural member, which has been taken as an assembly of short segments, is the same as in normal frame analysis. For the non-linear analysis, an iterative procedure is used with the loads applied in small increments. At each load increment step, direct iteration using the secant stiffness of the structure is employed. With this method, the loads may be applied either directly in the form of prescribed forces or indirectly in the form of prescribed displacements at the loading points. To generate the load-deflection curve of a beam subjected to a single PL at mid-span or two PLs at equal distance from midspan, prescribed displacements are applied at the loading points and the reactions at the loading points are taken as the applied loads. To generate the load-deflection curve of a beam subject to a UDL, prescribed forces are applied and the deflection at mid-span is taken as the deflection of the beam.

\subsection{Comparison with FE analysis results}

In part 1 of this paper (Ng et al., 2010), a number of beams were analysed by the FE method. All the beams have a uniform cross-section of $300 \mathrm{~mm}$ breadth by $600 \mathrm{~mm}$ depth and are simply supported over a span of $6000 \mathrm{~mm}$. The beams are identical except for the tension reinforcement ratio $\rho_{\mathrm{t}}$, which varies between 0.5 and $2.0 \%$. Nominal shear reinforcement of $0 \cdot 4 \%$ was provided in each beam. The material properties and other details of the beams have been presented in part 1. For each beam, two loading cases, that is PL at mid-span and a UDL over the entire span, were considered in the FE analysis.

The proposed member analysis method with tension stiffening taken into account is here applied to the above-mentioned beams to demonstrate the accuracy of the proposed method. In member analysis, the beam is divided into 20 frame elements, each of $300 \mathrm{~mm}$ length. When a PL is applied, the tensile stress block with $\alpha_{1}=0.4$ and $\alpha_{2}=18$ is used, while for a UDL, the tensile stress block with $\alpha_{1}=0.5$ and $\alpha_{2}=14$ is used. The member analysis results are found to agree closely with the FE analysis results. For illustration, the load-deflection curves of the beams with $\rho_{\mathrm{t}}=1 \cdot 0 \%$ obtained by member analysis and by FE analysis are presented in Figure 5. 
The opportunity is taken here to conduct a parametric study of the effects of adopting different values of $\alpha_{1}$ and $\alpha_{2}$ on the load-deflection curves of the beams. In the parametric study, three values of $\alpha_{1}(0 \cdot 3,0.4$ and 0.5$)$ and three values of $\alpha_{2}$ (10, 15 and 20) are considered, leading to a total of nine combinations of $\alpha_{1}$ and $\alpha_{2}$ values for the member analysis. For detailed evaluation, the member analysis and FE analysis results are compared in Tables 3 and 4. Since the discrepancy between the member analysis and FE analysis results varies along the load-deflection curve, the overall discrepancy is measured in terms of the maximum absolute error in secant stiffness (the load to deflection ratio) within the range from $0-90 \%$ of the peak load. From the comparison, it is seen that under a PL, the maximum absolute error in secant stiffness would be smallest and equal to $7 \cdot 1 \%$ when $\alpha_{1}=0.3$ and $\alpha_{2}=15$, whereas under a UDL, the maximum absolute error in secant stiffness would be smallest and equal to 8.5\% when $\alpha_{1}=0.4$ and $\alpha_{2}=10$. These optimum values of $\alpha_{1}$ and $\alpha_{2}$ perform better than the original values derived by combining the stress block at pre-crack state and the stress block at postcrack state together to form a single combined stress block because the combined stress block tends to overestimate the tensile stress when the beam has just cracked.

Having evaluated the effects of adopting different values of $\alpha_{1}$ and $\alpha_{2}$ on the accuracy of the member analysis, it is proposed, for improved performance, to fine-tune the $\alpha$ values for a PL as $\alpha_{1}=0.3$ and $\alpha_{2}=15$ and for a UDL as $\alpha_{1}=0.4$ and $\alpha_{2}=10$. Moreover, since the use of different stress blocks for different types of loading is inconvenient, it is proposed to unify the two

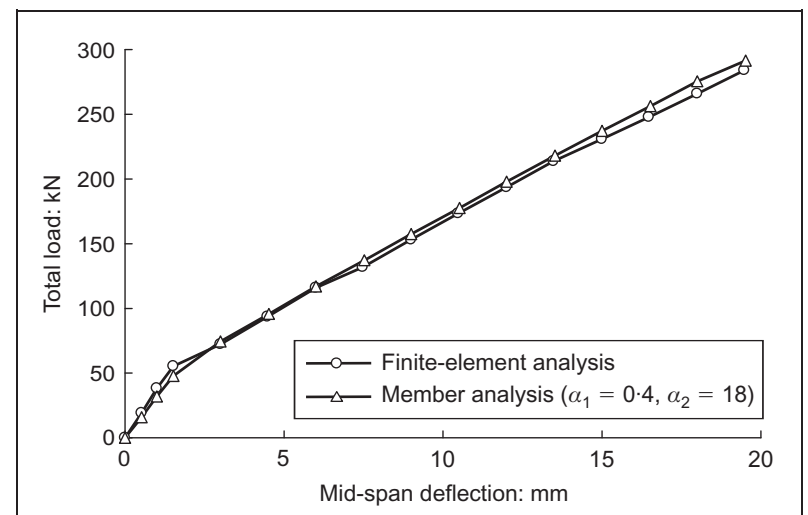

(a)

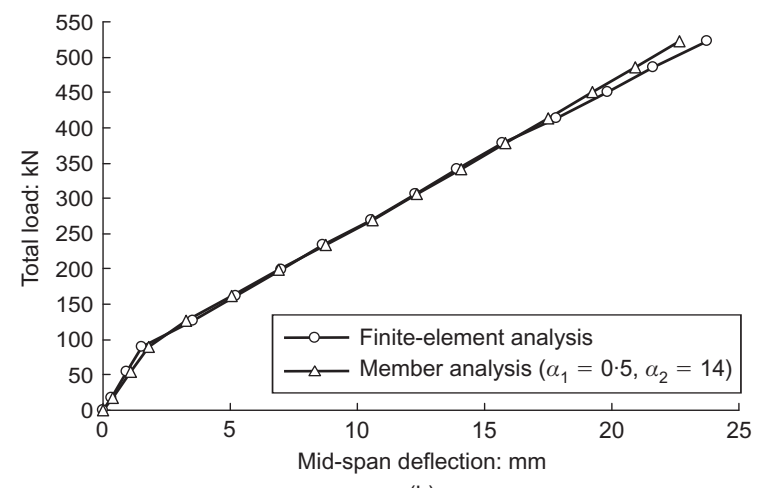

(b)

Figure 5. Comparison of member analysis and finite-element analysis results for a beam subjected to: (a) PL $\left(\rho_{\mathrm{t}}=1.0 \%\right)$; (b) UDL $\left(\rho_{\mathrm{t}}=1.0 \%\right)$ stress blocks for a PL and a UDL by setting $\alpha_{1}=0 \cdot 4$ and $\alpha_{2}=10$ for all types of loading. With this single set of $\alpha$ values adopted regardless of the type of loading, the maximum absolute error in secant stiffness would be smaller than 9\% under any loading case. The root mean square (RMS) errors in secant stiffness within the range $0-90 \%$ of the peak load were also evaluated. It was found that with the above set of $\alpha$ values adopted regardless of the type of loading, the maximum RMS error in secant stiffness would be smaller than 5\% under any loading case.

\subsection{Comparison with experimental results of Clark and Speirs (1978)}

In order to verify the applicability and accuracy of the finetuned and unified tensile stress block, the beams tested by Clark and Speirs (1978) were analysed and the theoretical moment-curvature and load-deflection curves so obtained compared with the experimental results. Four of the beams tested (beams 1 to 4) were selected for the analysis. All four beams have a uniform cross-section of approximately $200 \mathrm{~mm}$ breadth by $410 \mathrm{~mm}$ depth and an effective depth of about 370 $\mathrm{mm}$. They were each simply supported with a span of $3200 \mathrm{~mm}$ and subjected to two PLs applied at $600 \mathrm{~mm}$ from the mid-span location. The material properties and details of the beams are given in Table 5. Apart from minor differences in material properties and dimensions, the major difference between the four beams is that beams 1, 2, 3 and 4 have tension reinforcement ratios of 1.91, 1.28, 0.79 and 0.44\%, respectively. The theoretical and experimental results are compared for beams 1 and 2 in Figure 6 and for beams 3 and 4 in Figure 7. From Figures 6(a) and 7(a), it is evident that the theoretical results for the moment-curvature curves agree very closely with the experimental results. Likewise, from Figures 6(b) and 7(b), it is evident that the theoretical results for the load-deflection curves fit the experimental results well. Hence, the proposed analysis methods using the fine-tuned and unified stress block yield accurate results within the range of tension reinforcement ratios covered.

\subsection{Comparison with experimental results of Espion and Halleux (1988)}

To provide further evidence of the applicability of the finetuned and unified tensile stress block, the beams tested by Espion and Halleux (1988) were analysed and the theoretical moment-curvature and load-deflection curves so obtained compared with experimental results. Beams NO and N2, both having a uniform cross-section of $150 \mathrm{~mm}$ breadth by $280 \mathrm{~mm}$ depth, were selected for the analysis. In each beam, tension reinforcement was provided at a depth of $251 \mathrm{~mm}$ and compression reinforcement was provided at a depth of $34 \mathrm{~mm}$. Both beams were simply supported with a span of $3000 \mathrm{~mm}$ and subjected to two PLs at the third points. The material properties and details of the beams are presented in Table 6 , which shows that the two beams were provided with the same steel reinforcement, giving a tension reinforcement ratio of $1 \cdot 23 \%$ and a compression reinforcement ratio of $1 \cdot 23 \%$. The two beams are identical except that beam No was not subjected to axial loading whereas beam N2 was subjected to a constant axial compression load of $200 \mathrm{kN}$. Figure 8 shows a comparison of the theoretical and experimental results for the moment-curvature and load-deflection curves of the two beams. The figure shows that, for beam No, the theoretical 


\begin{tabular}{|c|c|c|c|c|c|}
\hline \multirow[t]{2}{*}{$\alpha_{1}$} & \multirow[t]{2}{*}{$\alpha_{2}$} & \multicolumn{4}{|c|}{ Maximum absolute error in secant stiffness: \% } \\
\hline & & $\rho_{\mathrm{t}}=0.5 \%$ & $\rho_{\mathrm{t}}=\mathrm{I} \cdot 0 \%$ & $\rho_{\mathrm{t}}=\mathrm{I} \cdot 5 \%$ & $\rho_{\mathrm{t}}=2 \cdot 0 \%$ \\
\hline \multirow[t]{3}{*}{0.3} & 10 & $12 \cdot 3$ & $7 \cdot 3$ & 6.6 & $5 \cdot 7$ \\
\hline & 15 & $7 \cdot 1$ & $4 \cdot 6$ & $7 \cdot 1$ & $6 \cdot 1$ \\
\hline & 20 & $4 \cdot 8$ & $3 \cdot 9$ & $7 \cdot 7$ & 6.5 \\
\hline \multirow[t]{3}{*}{0.4} & 10 & $8 \cdot 7$ & $3 \cdot 4$ & 6.7 & $5 \cdot 8$ \\
\hline & 15 & 6.1 & $4 \cdot 6$ & $7 \cdot 7$ & $6 \cdot 3$ \\
\hline & 20 & $7 \cdot 3$ & 4.9 & $8 \cdot 2$ & $6 \cdot 6$ \\
\hline \multirow[t]{3}{*}{0.5} & 10 & $7 \cdot 9$ & $7 \cdot 4$ & $7 \cdot 1$ & $6 \cdot 1$ \\
\hline & 15 & $12 \cdot 0$ & $8 \cdot 3$ & 8.0 & 6.7 \\
\hline & 20 & $13 \cdot 5$ & 9.0 & 9.0 & $7 \cdot 2$ \\
\hline
\end{tabular}

\begin{tabular}{|c|c|c|c|c|c|}
\hline \multirow[t]{2}{*}{$\alpha_{1}$} & \multirow[t]{2}{*}{$\alpha_{2}$} & \multicolumn{4}{|c|}{ Maximum absolute error in secant stiffness: \% } \\
\hline & & $\rho_{t}=0.5 \%$ & $\rho_{t}=\mathrm{I} \cdot 0 \%$ & $\rho_{t}=\mathrm{I} \cdot 5 \%$ & $\rho_{t}=2 \cdot 0 \%$ \\
\hline \multirow[t]{3}{*}{$0 \cdot 3$} & 10 & $7 \cdot 6$ & 6.0 & 9.5 & 8.0 \\
\hline & 15 & $4 \cdot 4$ & $6 \cdot 0$ & $9 \cdot 5$ & $7 \cdot 4$ \\
\hline & 20 & 3.9 & 6.0 & $9 \cdot 4$ & $7 \cdot 3$ \\
\hline \multirow[t]{3}{*}{0.4} & 10 & $4 \cdot 4$ & $4 \cdot 4$ & $8 \cdot 5$ & $5 \cdot 2$ \\
\hline & 15 & $8 \cdot 8$ & $5 \cdot 9$ & $8 \cdot 4$ & $8 \cdot 0$ \\
\hline & 20 & 11.4 & $6 \cdot 8$ & 8.4 & 4.7 \\
\hline \multirow{3}{*}{0.5} & 10 & $12 \cdot 1$ & $10 \cdot 3$ & 8.1 & 3.5 \\
\hline & 15 & $17 \cdot 6$ & $12 \cdot 2$ & $8 \cdot 1$ & $4 \cdot 4$ \\
\hline & 20 & $20 \cdot 2$ & $12 \cdot 7$ & $8 \cdot 1$ & $5 \cdot 0$ \\
\hline
\end{tabular}

\begin{tabular}{|c|c|c|c|c|}
\hline & Beam I & Beam 2 & Beam 3 & Beam 4 \\
\hline Concrete initial elastic modulus $E_{\mathrm{co}}: \mathrm{GPa}$ & $26 \cdot 5$ & $28 \cdot 0$ & $30 \cdot 3$ & $25 \cdot 0$ \\
\hline Concrete cylinder strength $f_{c}: M P a$ & $33 \cdot 8$ & $33 \cdot 3$ & $38 \cdot 1$ & 28.9 \\
\hline Concrete tensile strength $f_{\mathrm{t}}: \mathrm{MPa}$ & $2 \cdot 1$ & $2 \cdot 1$ & $3 \cdot 1$ & $2 \cdot 2$ \\
\hline Steel initial elastic modulus $E_{\mathrm{so}}: \mathrm{GPa}$ & 210 & 210 & 210 & 210 \\
\hline Breadth $b: \mathrm{mm}$ & 203 & 203 & 204 & 204 \\
\hline Overall depth $h: \mathrm{mm}$ & 410 & 408 & 407 & 409 \\
\hline Depth to tension reinforcement $\mathrm{d}: \mathrm{mm}$ & 380 & 363 & 373 & 379 \\
\hline Depth to compression reinforcement d': mm & 37 & 20 & 33 & 35 \\
\hline Area of tension reinforcement $A_{s t}: \mathrm{mm}^{2}$ & 1472 & 943 & 603 & 339 \\
\hline Area of compression reinforcement $A_{s c}: \mathrm{mm}^{2}$ & 402 & 101 & 101 & 101 \\
\hline
\end{tabular}

curves are almost identical to the experimental results. Moreover, although the possible effects of axial load have not been considered in the development of the proposed tensile stress block, for beam N2 subjected to axial load, the theoretical curves also agree very well with the experimental results. This indicates that the tensile stress block might also be applicable to flexural members subjected to axial loads. However, the evidence is too limited to draw any firm conclusions at this stage. Further research on tensile stress blocks in the presence of an axial load is recommended.

\section{MULTI-LEVEL ANALYSIS}

The above method may be extended to analysis of a complete frame structure using a multi-level approach of first dividing the frame structure into members, then analysing each member-by-member analysis in which the member is subdivided into many short segments, and finally dealing with each short segment by section analysis.

After dividing the frame structure into frame members, each frame member is subdivided into 20 or more segments with each segment treated as a frame element with two nodes. For each segment, the section stiffness matrix $[\mathrm{S}]$ is derived using Equations 6 and 7 and then the stiffness matrix $[\mathrm{K}]$ of the segment is derived using Equation 9. Having derived the stiffness matrix of each segment, the stiffness matrix of the frame member can be obtained by assembling the stiffness matrices of the segments together. Upon completion of the 


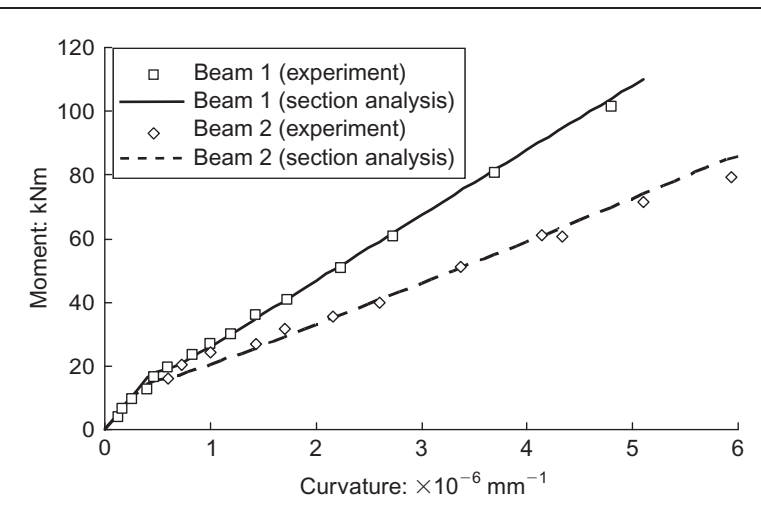

(a)

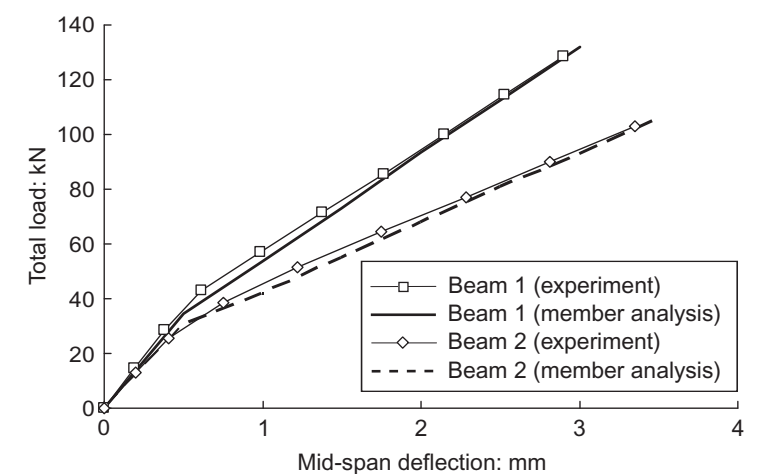

(b)

Figure 6. Comparison of section and member analysis results with the experimental results of Clark and Speirs (1978) for beams I and 2: (a) moment-curvature curve;

(b) load-deflection curve

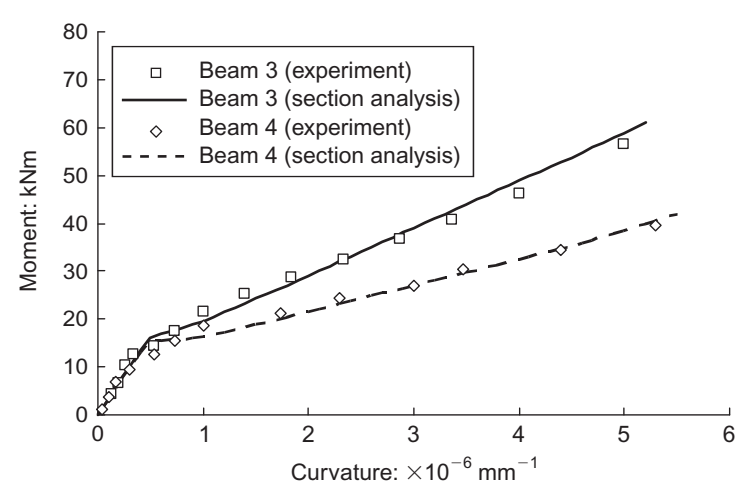

(a)

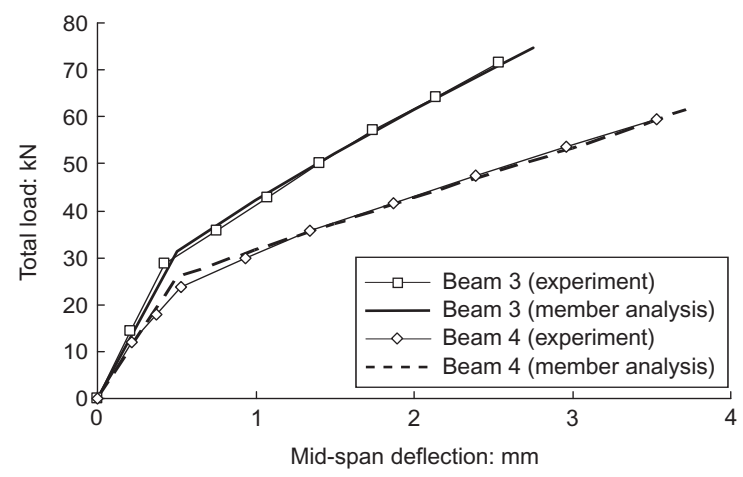

(b)

Figure 7. Comparison of section and member analysis results with the experimental results of Clark and Speirs (1978) for beams 3 and 4: (a) moment-curvature curve;

(b) load-deflection curve

\begin{tabular}{|c|c|c|}
\hline & Beam No & Beam N2 \\
\hline Concrete initial elastic modulus $E_{\mathrm{co}}: \mathrm{GPa}$ & $32 \cdot 5$ & 32.5 \\
\hline Concrete cylinder strength $f_{\mathrm{c}}: \mathrm{MPa}$ & $41 \cdot 6$ & $41 \cdot 6$ \\
\hline Concrete tensile strength $f_{\mathrm{t}}: \mathrm{MPa}$ & 4.0 & 4.0 \\
\hline Steel initial elastic modulus $E_{\mathrm{so}}: \mathrm{GPa}$ & 210 & 210 \\
\hline Breadth $b: \mathrm{mm}$ & 150 & 150 \\
\hline Overall depth $h: \mathrm{mm}$ & 280 & 280 \\
\hline Depth to tension reinforcement $\mathrm{d}: \mathrm{mm}$ & $25 I$ & 251 \\
\hline Depth to compression reinforcement d': mm & 34 & 34 \\
\hline Area of tension reinforcement $A_{\text {st }}: \mathrm{mm}^{2}$ & 462 & 462 \\
\hline Area of compression reinforcement $A_{s c}: \mathrm{mm}^{2}$ & 462 & 462 \\
\hline Axial load applied $\mathbf{P}: \mathbf{k N}$ & 0 & 200 \\
\hline
\end{tabular}

assembly process, the frame member should have two external nodes at its ends connected to the other parts of the frame structure and a number of internal nodes. As the internal nodes are not connected to any other parts of the frame structure, it should be computationally more efficient to treat each frame member as a substructure and eliminate the dof at the internal nodes by static condensation before proceeding further to analyse the complete frame structure. Having derived the stiffness matrix of each frame member, the overall stiffness matrix of the complete frame structure can be obtained by assembling the stiffness matrices of the frame members together.
In order to extend the analysis into post-crack and post-peak ranges, the secant stiffness matrix, which is always positive definite, is used in the formulation and direct iteration with the loads applied in increments is adopted in the numerical procedures. Further details of the analysis method and some preliminary results have been presented previously (Lam et al., 2007). To allow for tension stiffening at the post-crack state, the stress-strain relation of the concrete needs to be incorporated with an appropriate tensile stress block, as depicted here. To allow for strain increment reversal at the post-peak state (the axial strains in the steel reinforcement would eventually start to decrease as deformation of the 


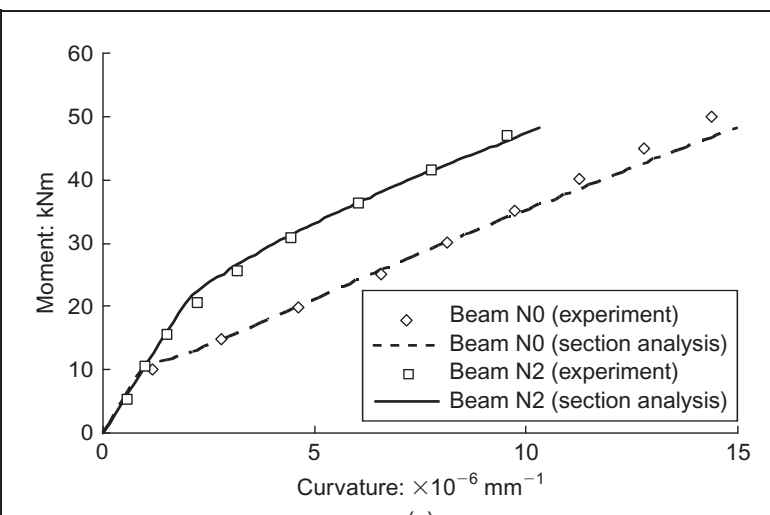

(a)

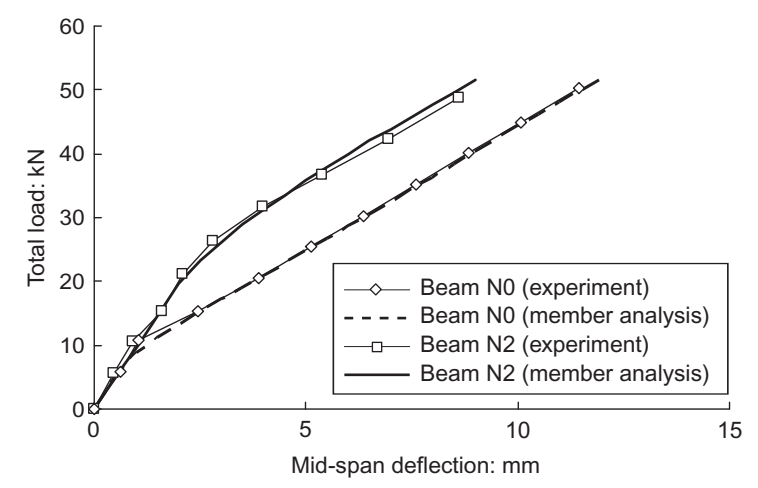

(b)

Figure 8. Comparison of section and member analysis results with the experimental results of Espion and Halleux (1988): (a) moment-curvature curve; (b) load-deflection curve

structure keeps on increasing), the stress-strain relation of the steel reinforcement needs to incorporate the stress-path dependence and residual strain, as explained in a previous study (Kwan et al., 2002). With both tension stiffening and strain increment reversal accounted for, full-range analysis covering the elastic, post-crack and post-peak states can be carried out. Such analysis should be useful for evaluating the serviceability, ductility and deformability of frame structures and for evaluating the ductility and deformability demands for different members in the structure. Further research along this line is being carried out and the results will be published in due course.

\section{CONCLUSIONS}

The tensile stress block proposed in part 1 of this paper based on FE analysis of cracked reinforced concrete beams has been compared to existing ones developed by others to provide an overall review. Although the existing tensile stress blocks differ widely, there is a group of tensile stress blocks having the common characteristic of comprising a linear ascending branch and a linear descending branch. The proposed tensile stress block, currently the only one directly derived from stress distribution results, also belongs to this group.

A section analysis method that is applicable to any arbitrarily shaped section subjected to axial load and biaxial bending has been presented. It is incorporated with the proposed tensile stress block and has been applied to analyse the beams tested by Sakai and Kakuta (1980). Comparison between the theoretical moment-curvature curves, the experimental results and the empirical curves given by the ACI building code and by Eurocode 2 revealed that they agree closely with each other, thus verifying the validity of the proposed tensile stress block and section analysis method.

A member analysis method that divides the frame member into many short segments and deals with each short segment by section analysis with the proposed tensile stress block has also been presented. It was applied to member analysis of the typical beams analysed by the FE method in part 1 of this paper. As expected, the member analysis results agree closely with the FE analysis results. Using this member analysis method, a parametric study of the effects of adopting different values for the parameters defining the shape of the tensile stress block was carried out. It was found that the proposed tensile stress block may be fine-tuned to improve its accuracy and the two tensile stress blocks proposed for different types of loading may be unified to become one tensile stress block for any type of loading. The fine-tuned and unified tensile stress block was applied to analyse beams tested by Clark and Speirs (1978) and Espion and Halleux (1988). The good agreement between the theoretical and experimental results verified the applicability and accuracy of the fine-tuned and unified tensile stress block and member analysis method.

Lastly, a multi-level method for the non-linear load-deflection analysis of frame structures has been developed as an extension of the proposed member analysis method. It first divides the frame structure into frame members and then subdivides each frame member into 20 or more segments. Each segment is treated as a frame element with its stiffness matrix derived by the section and member analysis methods presented here. Having derived the stiffness matrix of each segment, the stiffness matrix of each frame member and the overall stiffness matrix of the frame structure may then be obtained by the usual assembly process. With tension stiffening and strain increment reversal properly accounted for, such multi-level analysis may be applied to full-range analysis covering the elastic, post-crack and post-peak states for evaluating the serviceability, ductility and deformability of frame structures. Further research using this multi-level approach is highly recommended and is in fact being carried out by the authors.

\section{REFERENCES}

ACI (American Concrete Institute) (2008) ACI 318M-08. Building Code Requirements for Structural Concrete and Commentary, Manual of Concrete Practice. ACI, Farmington Hills, MI.

Beeby AW, Scott RH and Jones AEK (2005) Revised code provisions for long-term deflection calculations. Proceedings of the Institution of Civil Engineers, Structures and Buildings 158(1): 71-75.

Branson DE (1968) Design procedures for computing deflection. ACI Journal 65(9): 730-742.

BSI (British Standards Institution) (1985) BS 8110. Structural Use of Concrete, Part 2: Code of Practice for Special Circumstances. BSI, London.

Carreira DJ and Chu K (1986) The moment-curvature relationship of reinforced concrete members. ACI Journal 83(2): 191-198.

Clark LA and Cranston WB (1979) The influence of bar spacing 
on tension stiffening in reinforced concrete slabs. Advance on Concrete Slab Technology: Proceedings of an International Conference on Concrete Slabs (Dhir RK and Munday JGL (eds)). Dundee University, pp. 118-128.

Clark LA and Speirs DM (1978) Tension Stiffening in Reinforced Concrete Beams and Slabs Under Short-Term Load. Cement and Concrete Association, London, Technical report 42.521.

CEB (Comité Euro-International du Béton) (1993) CEB-FIP Model Code 1990: Model Code for Concrete Structures. Thomas Telford, London.

CEN (Comité Européen de Normalisation) (2005) Eurocode 2: Design of Concrete Structures: Part 1-1: General Rules and Rules for Buildings. British Standards Institution, London, BS EN 1992-1-1: 2004.

Damjanic F and Owen DRJ (1984) Practical considerations for modelling of post-cracking concrete behaviour for finiteelement analysis of reinforced concrete structures. Proceedings of an International Conference on Computer Aided Analysis and Design of Concrete Structures (Damjanic F et al. (eds)). Pineridge Press, Swansea, pp. 693-706.

Espion B and Halleux P (1988) Moment-curvature relationship of reinforced concrete sections under combined bending and normal force. Materials and Structures 21(125): 341-351.

Gilbert RI and Warner RF (1978) Tension stiffening in reinforced concrete slabs. ASCE Journal of Structural Engineering Division 104(12): 1885-1900.

Kaklauskas G and Ghaboussi J (2001) Stress-strain relations for cracked tensile concrete from RC beam tests. ASCE Journal of Structural Engineering 127(1): 64-73.

Kwan KH and Liauw TC (1985) Computerized ultimate strength analysis of reinforced concrete sections subjected to axial compression and biaxial bending. Computers and Structures 21(6): 1119-1127.

Kwan AKH, Ho JCM and Pam HJ (2002) Flexural strength and ductility of reinforced concrete beams. Proceedings of the
Institution of Civil Engineers, Structures and Buildings 152(4): 361-369.

Lam JYK, Ng PL and Kwan AKH (2007) Nonlinear multilevel analysis of reinforced concrete beams. Proceedings of the 11th International Conference on Civil, Structural and Environmental Engineering Computing, St. Julians, Malta. CD-Rom, paper 164.

Liauw TC and Kwan KH (1984) Computerized modular ratio design of reinforced concrete members subjected to axial load and biaxial bending. Computers and Structures 18(5): 819-832.

Ng PL, Lam JYK and Kwan AKH (2010) Tension stiffening in reinforced concrete beams. Part 1: FE analysis. Proceedings of the Institution of Civil Engineers, Structures and Buildings 163(1): 19-28.

Prakhya GKV and Morley CT (1990) Tension stiffening and moment-curvature relations of reinforced concrete elements. ACI Structural Journal 87(5): 597-605.

Saenz LP (1964) Discussion of 'Equation for the stress-strain curve of concrete' by Desayi and Krishnan. ACI Journal 61(9): 1229-1235.

Sakai K and Kakuta Y (1980) Moment-curvature relationships of reinforced concrete members subjected to combined bending and axial force. ACI Journal 77(3): 189-194.

Schnobrich WC (1985) Role of finite element analysis of reinforced concrete structures. Proceedings of Seminar on Finite Element Analysis of Reinforced Concrete Structures (Meyer C and Okamura H (eds)). New York, ASCE, pp. 1-24.

Scott RH (1983) The short-term moment-curvature relationship for reinforced concrete beams. Proceedings of the Institution of Civil Engineers, Part 2 75(December): 725-734.

Torres Ll, Lopez-Almansa F and Bozzo LM (2004) Tensionstiffening model for cracked flexural concrete members. ASCE Journal of Structural Engineering 130(8):

$1242-1251$.

\section{What do you think?}

To discuss this paper, please email up to 500 words to the editor at journals@ice.org.uk. Your contribution will be forwarded to the author(s) for a reply and, if considered appropriate by the editorial panel, will be published as discussion in a future issue of the journal.

Proceedings journals rely entirely on contributions sent in by civil engineering professionals, academics and students. Papers should be 2000-5000 words long (briefing papers should be 1000-2000 words long), with adequate illustrations and references. You can submit your paper online via www.ice.org.uk/journals, where you will also find detailed author guidelines. 